\title{
Effects of HPV-16 infection on hypopharyngeal squamous cell carcinoma and FaDu cells
}

\author{
WUHAO LU ${ }^{1 *}$, LONG FENG $^{2 *},{\text { PING } \mathrm{LI}^{3}, \text { YUANYUAN WANG }}^{4}$, YUWEN DU ${ }^{4}$, \\ XIAONAN CHEN ${ }^{4}$, SHUJUN WU ${ }^{3}$, GUOQIANG ZHAO ${ }^{4}$ and WEIHUA LOU ${ }^{1}$

\begin{abstract}
${ }^{1}$ Department of Otolaryngology-Head and Neck Surgery, The First Affiliated Hospital, Zhengzhou University, Zhengzhou, Henan 450052; ${ }^{2}$ Department of Pathogenic Organism Biology, Henan University of TCM, Zhengzhou, Henan 450008;

${ }^{3}$ Department of Respiratory Medicine, The First Affiliated Hospital of Zhengzhou University, Zhengzhou, Henan 450052;

${ }^{4}$ College of Basic Medical Sciences, Zhengzhou University, Zhengzhou, Henan 450001, P.R. China
\end{abstract}

Received June 18, 2015; Accepted July 30, 2015

DOI: $10.3892 /$ or.2015.4340

\begin{abstract}
Hypopharyngeal squamous cell carcinoma is a common type of malignant tumor among head and neck squamous cell carcinomas (HNSCCs). Heavy smoking and/ or drinking is associated with the development of HNSCC. However, HNSCC also occurs in individuals that do not drink or smoke, possibly due to infection with the human papilloma virus (HPV). HPV-16 has been shown to be closely associated with the occurrence of several types of cancers. However, its role in hypopharyngeal squamous cell carcinoma remains unclear. In the present study, we investigated the effects of HPV-16 on hypopharyngeal squamous cell carcinoma and $\mathrm{FaDu}$ cells. Lentiviral vectors were used to establish $\mathrm{FaDu}$ cells that expressed the E6 and E7 proteins of HPV-16. We used quantitative reverse transcription-polymerase chain reaction (qRT-PCR) assays and western blotting to detect and determine the levels of expression for E6-E7 mRNAs and proteins. Cell Counting Kit-8 (CCK-8) assays, enzyme-linked immunosorbent assays (ELISA), Transwell assays, and flow cytometry were used to assess the effects of HPV-16 E6-E7 on the proliferation, invasion, metastasis and apoptosis of $\mathrm{FaDu}$ cells. Expression of microRNAs was analyzed by qRT-PCR. We found that the expression levels of HPV-16 E6-E7 were increased in FaDu cells transfected with the lentiviral vector
\end{abstract}

Correspondence to: Dr Wuhao Lu, Department of OtolaryngologyHead and Neck Surgery, First Affiliated Hospital, Zhengzhou University, 1 Jianshe Road, Zhengzhou, Henan 450052, P.R. China E-mail: luwuhao@126.com

Professor Guoqiang Zhao, College of Basic Medical Sciences, Zhengzhou University, 100 Kexue Road, Zhengzhou, Henan 450001, P.R. China

E-mail: zhaogq@126.com

*Contributed equally

Key words: invasion, apoptosis, microRNA, HPV, hypopharyngeal squamous cell carcinoma compared with that observed in the control cells. In addition, the rates of apoptosis were decreased in the transfected cells, while proliferation was increased. The average numbers of cells penetrating the Matrigel were significantly higher than those for the controls. We detected miR-363 and miR-15a, and their expression levels were significantly increased in the HPV-16-positive patients and in FaDu cells expressing HPV-16 E6-E7. We found that HPV-16 E6-E7 appeared to inhibit apoptosis, and to increase cell proliferation, invasion and metastasis. Furthermore, miR-363 and miR-15a were overexpressed in the hypopharyngeal squamous cell carcinoma samples infected with HPV-16, and in FaDu cells stably expressing HPV-16 E6-E7. These findings may provide a new clue of the mechanisms involved in the pathogenesis of HPV-16-positive hypopharyngeal squamous cell carcinoma.

\section{Introduction}

Head and neck squamous cell carcinoma (HNSCC) is the sixth most common cancer in the world (1). It is characterized by phenotypical, etiological, biological and clinical heterogeneity. Despite surgery, radiation therapy, and chemotherapy, approximately half of all patients die (2-4). Laryngeal squamous cell carcinoma and hypopharyngeal squamous cell carcinoma are two common malignancies of HNSCC that mainly occur in middle-aged men. Tobacco smoking and alcohol abuse are predominant risk factors in HNSCC. A subset of oropharyngeal carcinoma cases are strongly associated with the infection of high-risk human papilloma virus (HPV), predominantly HPV-16 (5-7). The oncogenicity of high-risk HPV is dependent on the constitutive expression of oncogenes, such as E6 and E7 (8-15).

The E6 and E7 genes of the HPV-16 genome encode the oncoproteins E6 and E7, respectively $(16,17)$. Lentiviral vectors can be used to transfect cells with high efficiency, allowing for the stable integration of genes into cells. MicroRNAs are involved in almost all biological processes in the human body, including cell proliferation, differentiation, apoptosis, invasion and migration (18-20). Abnormal expression of miRNAs is associated with the occurrence and development of many types of tumors (21-23). 
Table I. miR-155, miR-363, miR-15A and U6 reverse transcription primers.

\begin{tabular}{lll}
\hline Gene name & \multicolumn{1}{c}{ RT primers } & \multicolumn{1}{c}{ PCR primers } \\
\hline miR-155 & 5'-GTCGTATCCAGTGCAGGGTCCGAGG & F 5'-TCCGATGGGGATAGTGCTAAT-3' \\
& TATTCGCACTGGATACGACAATTACG-3' & R 5'-GTGCAGGGTCCGAGGT-3' \\
miR-363 & 5'-GTCGTATCCAGTGCAGGGTCCGAGG & F 5'-TCCGATTTAACGTAGCACTA-3' \\
& TATTCGCACTGGATACGACGCCCACC-3' & R 5'-GTGCAGGGTCCGAGGT-3' \\
miR-15A & 5'-GTCGTATCCAGTGCAGGGTCCGAGG & F 5'-TCCGAGTGTTTGGTAATACA-3' \\
& TATTCGCACTGGATACGACATCGTCG-3' & R 5'-GTGCAGGGTCCGAGGT-3' \\
U6 nRNA & 5'-GTCGTATCCAGTGCAGGGTCCGAGG & F 5'-TCCGATCGTGAAGCGTTC-3' \\
& TATTCGCACTGGATACGACAAAATA-3' & R 5'-GTGCAGGGTCCGAGGT-3' \\
\hline
\end{tabular}

In the present study, we used a lentiviral vector to transfect and integrate the HPV-16 E6-E7 genes into the hypopharyngeal squamous cell carcinoma cell line, FaDu. We then observed the effects of E6-E7 expression on these cells. We also sought to determine any effects of HPV-related miRNAs on HNSCC by examining miRNA expression levels in hypopharyngeal squamous cell carcinoma tissues.

\section{Materials and methods}

Patients and tumor samples. Tumor samples were collected from 28 patients with pharyngeal cancer who had undergone surgery at the Department of Otolaryngology-Head and Neck Surgery, The First Affiliated Hospital of Zhengzhou University (Zhengzhou, China). Patients recruited to this study had not undergone previous chemotherapy, radiotherapy or immunotherapy. Collected tumor samples were frozen in liquid nitrogen and then stored at $-80^{\circ} \mathrm{C}$ until required. This study was approved by the Ethics Committee of Zhengzhou University, and informed consent was obtained from each patient.

HPV DNA detection and typing. We detected the presence of HPV genes in fresh frozen samples using polymerase chain reaction (PCR) assays followed by reverse dot blots. Using PCR, 28 HPV gene segments were amplified. These were then hybridized to specific probes that were affixed to membranes. The probes we used corresponded with 5 low-risk and 18 high-risk HPV genotypes.

Cell culture. The hypopharyngeal squamous cell carcinoma cell line, FaDu, along with the Hep-2 and 293 T cell lines, were purchased from the Type Culture Collection of the Chinese Academy of Sciences (Shanghai, China). Cells were cultured in Dulbecco's modified Eagle's medium (DMEM) supplemented with $10 \%$ fetal bovine serum (FBS) (both from Gibco, USA) and grown in a $37^{\circ} \mathrm{C}, 5 \% \mathrm{CO}_{2}$ incubator.

Integration, transfection, and expression of HPV-16 E6-E7 genes. HPV-16 E6-E7 genes were amplified and cloned into the pLV-EGFP-C lentiviral vector, between the HindIII and $K p n I$ sites, to produce the recombinant lentivirus LV-HPV16-E6-E7. The empty pLV-EGFP-C vector was used as an empty vector control. We co-transfected $5 \mu \mathrm{g}$ of LV-HPV-
16-E6-E7 with $3.75 \mu \mathrm{g}$ of $\mathrm{pH} 1$ and $1.25 \mu \mathrm{g}$ of $\mathrm{pH} 2$ into $293 \mathrm{~T}$ packaging cells using PolyFect-V (Invitrogen, USA). After incubation at $37^{\circ} \mathrm{C} / 5 \% \mathrm{CO}_{2}$ for $48 \mathrm{~h}$, the culture medium was harvested and concentrated 100 - to 200 -fold by ultrafiltration. Virus titers in the concentrated supernatants were determined on 293T cells based on the expression level of enhanced green fluorescent protein (EGFP). Cells were cultured in DMEM containing $10 \% \mathrm{FBS}$, and infected at a multiplicity of infection of 10-30 in the presence of $6 \mu \mathrm{g} / \mathrm{ml}$ Polybrene (Sigma-Aldrich, St. Louis, MO, USA) and $1 \mathrm{mg} / \mathrm{ml}$ puromycin. Cell culture medium was changed every $72 \mathrm{~h}$. Positive clones were identified through the expression of EGFP.

$R N A$ isolation and quantitative reverse transcription$P C R$ ( $q R T-P C R)$ assays. RNA was extracted from FaDu and Hep-2 cells using E.Z.N.A. ${ }^{\circledR}$ Total RNA kit I (Omega Bio-Tek, Norcross, GA, USA), according to the manufacturer's instructions. Reverse transcription and PCR amplification were performed using a qRT-PCR quantitation kit (Novland, China). An ABI 7500 HT Sequence Detection system (Applied Biosystems, Foster City, CA, USA) was used to determine the relative levels of E6 and E7 mRNAs in the cells. Primers and probes designed for TaqMan assays were purchased from Applied Biosystems. Amplification was conducted according to the manufacturer's instructions. Results from the qRT-PCR assays were analyzed by the $2^{-\Delta \Delta \mathrm{Ct}}$ method (24).

Western blot analysis. FaDu cells infected with LV-HPV-16-E6-E7, uninfected FaDu cells, Hep-2 cells, and cells transfected with the empty pLV-EGFP-C vector were lysed, and total proteins were isolated. Total protein concentration was determined using a Bradford assay. We used $30 \mu \mathrm{g}$ of total protein per sample for sodium dodecyl sulfate-polyacrylamide gel electrophoresis, with $12 \%$ polyacrylamide gels. Electrophoresed proteins were transferred to nitrocellulose membranes (GE Healthcare, USA), which were subsequently blocked with $5 \%(\mathrm{w} / \mathrm{v})$ non-fat milk and incubated overnight at $4^{\circ} \mathrm{C}$ with antibodies against HPV E6 (diluted 1:800; Cell Signaling Technology, Danvers, MA, USA) and HPV E7 (1:400; Santa Cruz Biotechnology, Santa Cruz, CA, USA). The membranes were then incubated with the appropriate horseradish peroxidase-conjugated secondary antibody $(1: 2,000$; Santa Cruz Biotechnology). The intensity of the protein bands was evaluated using a Molecular Dynamics densitometer 


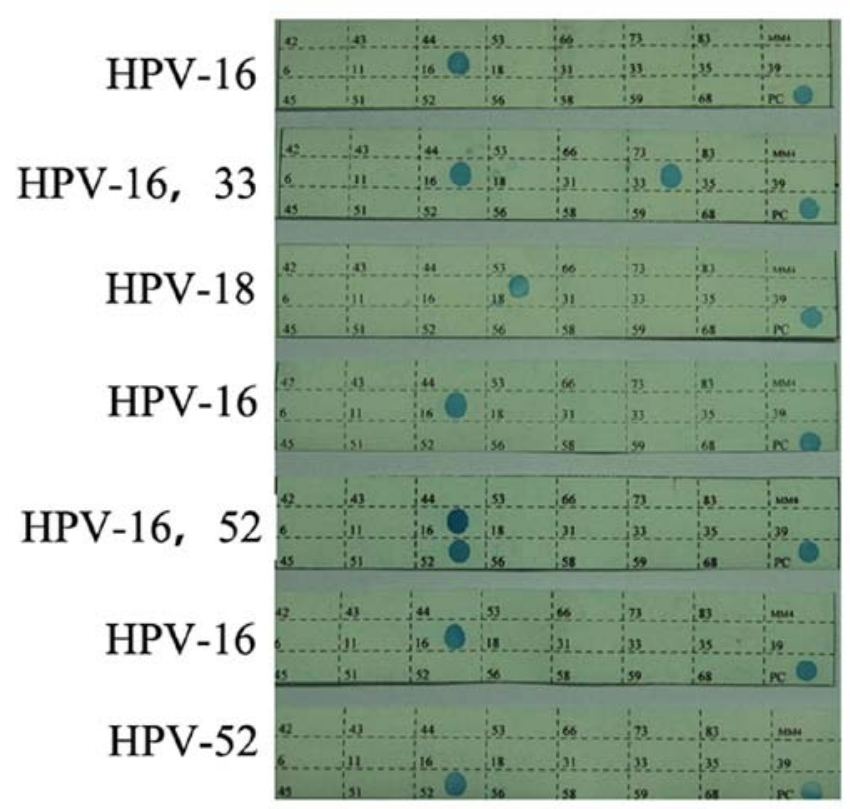

Figure 1. Sample test of 7 cases of HPV-positive pharyngeal squamous carcinoma tissues. Five cases had a single type of HPV infection, of which 3 cases presented with type HPV-16, 1 case presented with type HPV-18, and 1 case presented with type HPV-52. Two cases presented with two types of HPV infections; 1 case had types HPV-16 and -33, and one case had types HPV-16 and -52 .

(Molecular Dynamics, Sunnyvale, CA, USA). We used glyceraldehyde 3-phosphate dehydrogenase as an internal reference.

Cell proliferation assays. Cell proliferation was evaluated using Cell Counting Kit-8 reagents (CCK-8; Dojindo, Japan). Cells in the logarithmic phase of growth were seeded in 96-well plates at a density of $1 \times 10^{4}$ cells/well. We added $10 \mu \mathrm{l}$ of CCK-8 to each well on 5 consecutive days, at the same time each day. The optical density at $450 \mathrm{~nm}$ in each well was assessed using an ELx800 microplate reader (BioTek, Winooski, VT, USA). All experiments were conducted in triplicate.

Cell cycle analysis. Cells in the logarithmic phase of growth were harvested by trypsinization, washed with phosphate-buffered saline (PBS), and fixed with $75 \%$ ethanol overnight at $4^{\circ} \mathrm{C}$. Cells were then incubated with RNase at $37^{\circ} \mathrm{C}$ for 30 min, and stained with propidium iodide (PI) for $30 \mathrm{~min}$. We examined $10^{6}$ events/sample using a BD FACSCalibur ${ }^{\mathrm{TM}}$ (BD Biosciences, San Jose, CA, USA). All experiments were performed in triplicate.

Apoptosis assays. The Annexin V-FITC Apoptosis Detection kit (Abcam, USA) was used to detect and quantify apoptosis by flow cytometry. Briefly, cells in the logarithmic phase of growth were harvested using cold PBS and centrifuged (5 min at $1,000 \mathrm{x} \mathrm{g}$ ). The cells were resuspended in binding buffer at a density of $1 \times 10^{6}$ cells $/ \mathrm{ml}$, stained with FITC-labeled Annexin $\mathrm{V}$ for $5 \mathrm{~min}$, and subjected to flow cytometry on a BD FACSCalibur ${ }^{\mathrm{TM}}$. Samples were tested in triplicate and analyzed with CellQuest software (BD Biosciences).

Transwell assays. Cell invasion assays were performed using Transwell chambers with $8.0-\mu \mathrm{m}$ pores (Costar, Cambridge, NY, USA). Basement membrane matrix was added to the top chambers and allowed to solidify for $30 \mathrm{~min}$ at $37^{\circ} \mathrm{C}$. We added
$500 \mu 1$ of culture medium containing chemotactic factor into the lower chamber. Cells were then seeded into the top chambers at a density of $5 \times 10^{5}$ cells/well and allowed to incubate at $37^{\circ} \mathrm{C}$ for $24 \mathrm{~h}$. Cells were then fixed with paraformaldehyde, stained with $0.1 \%$ crystal violet, and quantified. Experiments were independently repeated six times, in quadruplicate.

miRNA expression assays. We isolated miRNAs using TRIzol reagent (Invitrogen) according to the manufacturer's instructions. For reverse transcription and qPCR assays, we used miR-155, miR-363, miR-15A or U6 as primers (Table I). Assays were independently repeated three or more times.

Statistical analysis. All statistical analyses were performed using SPSS 17.0 (SPSS Inc., Chicago, IL, USA) software. Student's t-test was used to compare the mean between two samples. Multiple comparisons between parental and control vector groups were made using Tukey's honest significant difference test. The expression levels of miRNAs in cells and tissues were analyzed using the Wilcoxon signed-rank test. Values are presented as the mean \pm SD. A p-value $<0.05$ was considered statistically significant.

\section{Results}

Presence of HPV in the specimens and clinical features of the hypopharyngeal squamous cell carcinoma cases. We observed indicators of HPV infection in 25\% (7/28) of the hypopharyngeal squamous cell carcinoma cases (Table II and Fig. 1). The criteria used to define heavy smoking were: an individual that smoked for more than 20 years; and smoked not less than one pack per day. The criteria used to define heavy drinking were: an individual that had regularly consumed alcohol for more than 20 years; and drank not less than $150 \mathrm{~g}$ of alcohol per day. Patients were separated into two groups for statistical 
Table II. HPV infection in patients ( 7 cases) showing patient no. and type of HPV infection.

\begin{aligned} & \hline HPV-positive patient no. Type of HPV infection \\ & \hline 3 HPV-16 \\ & 8 HPV-16, HPV-33 \\ & 10 HPV-18 \\ & 15 HPV-16 \\ & 18 HPV-16, HPV-52 \\ & 21 HPV-16 \\ & 26 HPV-52 \\ & \hline\end{aligned}

analyses: HPV-positive and HPV-negative. There was a significant difference between the two groups when heavy smoking was considered as a variable $(\mathrm{P}<0.05$, Table III). Differences between the two groups of patients with respect to age, gender, pathological type, and tumor $\mathrm{T}$ stage were not significantly different $(\mathrm{P}>0.05$, Table III).

Overexpression of HPV-16 E6-E7. Positive clones were identified through the expression of EGFP. We observed E6-E7 expression in stably transfected FaDu cells at the mRNA and protein levels. The relative E6-E7 mRNA levels in the HPV-16 E6-E7 FaDu cells $(2.6 \pm 0.22,1.8 \pm 0.12)$ were higher than these levels in the empty vector control cells $(0.003 \pm 0.0001$, $0.003 \pm 0.0002, \mathrm{P}<0.05)$ and blank control cells (FaDu cells) $(0.002 \pm 0.0002,0.005 \pm 0.0001, \mathrm{P}<0.05)$, while consistent with the Hep-2 cells (Table IV and Fig. 2).

HPV-16 E6-E7 promotes FaDu cell proliferation. We observed that HPV-16 E6-E7 promoted the proliferation of FaDu cells in vitro (Fig. 3), and that these effects were dependent on time. Proliferation levels were maximal after 5 days.

HPV-16 E6-E7 inhibits the apoptosis of FaDu cells. Apoptosis was determined using flow cytometry and caspase-3- and caspase-9-specific enzyme-linked immunosorbent assays (ELISAs). We observed a significant decrease in the number of Annexin $\mathrm{V}^{+}$apoptotic FaDu cells that were stably transfected compared with the numbers in the cells containing the empty vector $(7.246 \pm 0.815$ vs. $13.464 \pm 0.609 \%$; $\mathrm{P}<0.05)$ or blank control (7.246 \pm 0.815 vs. $13.298 \pm 1.324 \%$; $\mathrm{P}<0.05)$. According to our ELISA results, no significant difference was noted between the blank and empty vector control $(\mathrm{P}>0.05)$, while there was a significant difference with the HPV-16 E6-E7 group (Fig. 4).

HPV-16 E6-E7 reduces G0/G1 arrest in the FaDu cells and promotes progression of the cell cycle and cell proliferation. The proportions of $\mathrm{FaDu}$ cells in the G0/G1 phase of the cell cycle were $53.816 \pm 1.665,62.284 \pm 1.609$, and $62.262 \pm 2.139 \%$ for those that were stably transfected, those transfected with the empty vector, and the blank control, respectively (Fig. 5).

HPV-16 E6-E7 increases the invasive ability of the FaDu cells. Our in vitro cell invasion assay results showed that
Table III. Analysis of the HPV status and the laryngopharyngeal carcinoma clinical characteristics of the cases.

\begin{tabular}{|c|c|c|c|c|}
\hline Factors & $\begin{array}{c}\text { HPV } \\
\text { positive } \\
(\mathrm{n})\end{array}$ & $\begin{array}{c}\text { HPV } \\
\text { negative } \\
\text { (n) }\end{array}$ & $\chi^{2}$-value & P-value \\
\hline Age (years) & & & 3.111 & 0.078 \\
\hline$\leq 60$ & 5 & 7 & & \\
\hline$>60$ & 2 & 14 & & \\
\hline Gender & & & 0.718 & 0.397 \\
\hline Male & 6 & 20 & & \\
\hline Female & 1 & 1 & & \\
\hline $\begin{array}{l}\text { Heavy drinking } \\
\text { /smoking }\end{array}$ & & & 8.400 & $0.004^{\mathrm{a}}$ \\
\hline Yes & 2 & 18 & & \\
\hline No & 5 & 3 & & \\
\hline Pathological type & & & 1.600 & 0.449 \\
\hline High & 2 & 2 & & \\
\hline Moderate & 2 & 3 & & \\
\hline Poor & 3 & 16 & & \\
\hline Tumor T stage & & & 1.159 & 0.763 \\
\hline $\mathrm{T} 1$ & 1 & 1 & & \\
\hline $\mathrm{T} 2$ & 2 & 5 & & \\
\hline $\mathrm{T} 3$ & 3 & 13 & & \\
\hline $\mathrm{T} 4$ & 1 & 2 & & \\
\hline
\end{tabular}

${ }^{\mathrm{a}}$ Indicates statistical significance $(\mathrm{P}<0.05)$.

Table IV. HPV-16 E6-E7 mRNA relative expression.

\begin{tabular}{lccc}
\hline Cell groups & $\mathrm{n}$ & E6 mRNA & E7 mRNA \\
\hline $\begin{array}{l}\text { HPV-16 E6-E7 } \\
\text { Empty vector }\end{array}$ & 5 & $2.6 \pm 0.22$ & $1.8 \pm 0.12$ \\
$\begin{array}{l}\text { control } \\
\text { Blank control } \\
\text { (FaDu cells) }\end{array}$ & 5 & $0.002 \pm 0.0002$ & $0.005 \pm 0.0001$ \\
Hep-2 cells & 5 & $2.3 \pm 0.21$ & $1.7 \pm 0.11$
\end{tabular}

HPV-16 E6-E7 promoted the invasive ability of the FaDu cells when compared with the control cells (Fig. 6). These results demonstrate that HPV-16 E6-E7 promotes the invasive ability of FaDu cells in vitro.

miR-363 and miR-15a are overexpressed in the HPV-positive hypopharyngeal squamous cell carcinoma samples. Relative expression levels of miR-363 and miR-15a were significantly higher in the HPV-positive specimens than these levels in the HPV-negative specimens. We did not observe a significant difference in miR-155 levels for specimens that were HPV-positive/negative and in FaDu cells that stably expressed HPV-16 E6-E7 (Fig. 7). 


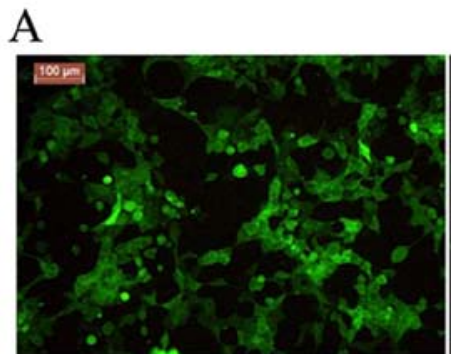

HPV-16 E6-E7

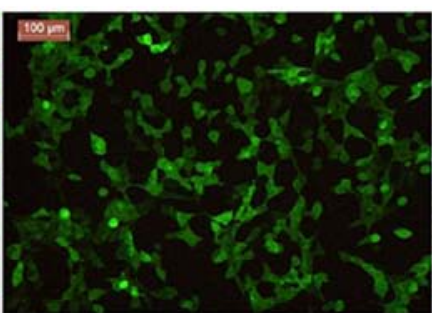

Empty vector control

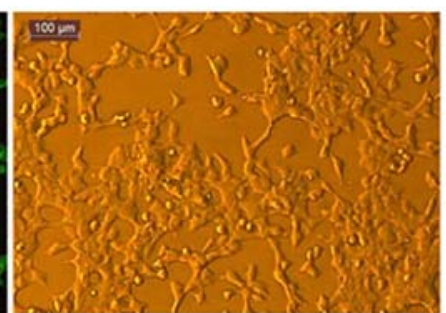

Blank control
B

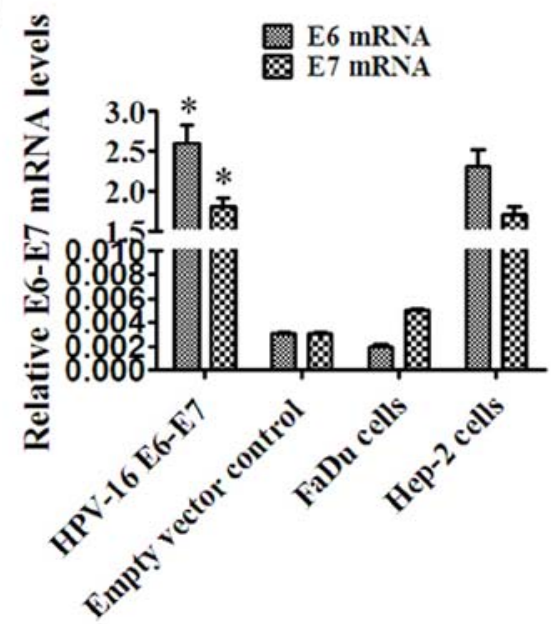

$\mathrm{C}$

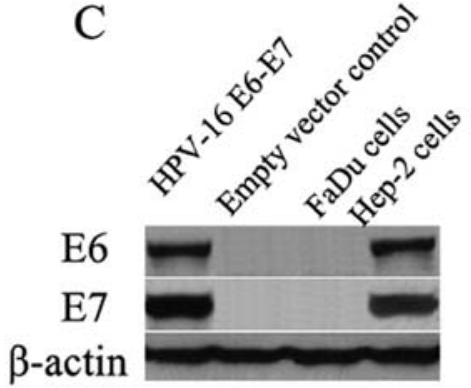

Figure 2. E6-E7 is overexpressed in the stably transfected FaDu cells. (A) Positive clones were identified by positive EGFP expression. (B) Expression levels of E6-E7 mRNA in the three groups of FaDu cells and in the Hep-2 cells. (C) Expression levels of E6-E7 protein in the three groups of FaDu cells and in the Hep-2 cells. $\beta$-actin served as a loading control to verify that equal amounts of protein were present in each lane $\left({ }^{*} \mathrm{P}<0.05\right)$.

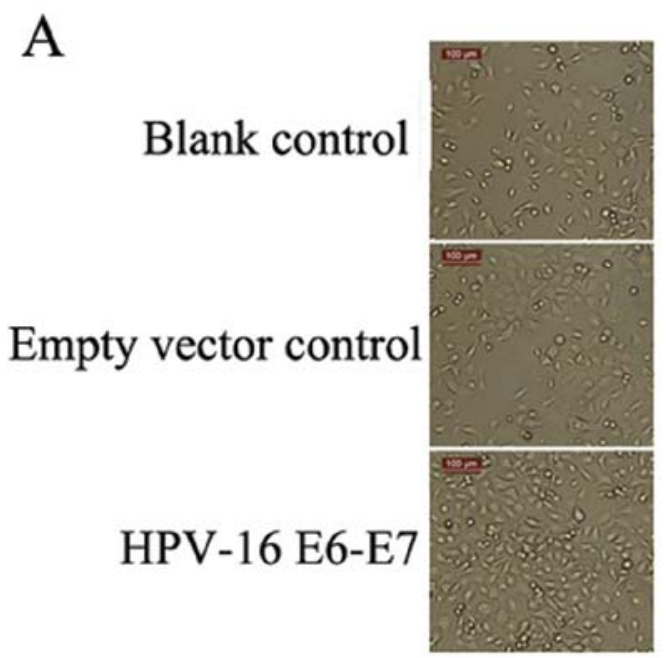

B

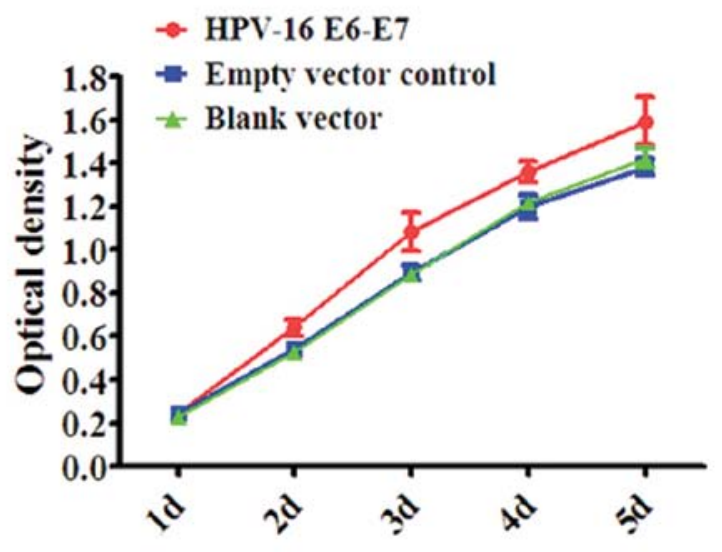

Figure 3. Cell proliferation of the FaDu cells transfected with the LV-HPV-16-E6-E7 lentivirus was assessed using the CCK-8 assay. Data are presented as the mean of triplicate experiments. (A) Comparison of the status of cell growth at $48 \mathrm{~h}$. (B) The growth promoting effect of the HPV-16 E6-E7 lentivirus was time-dependent, with a maximum effect detected at day 5 achieving a significant difference $(\mathrm{P}<0.05)$.

\section{Discussion}

It is estimated that HNSCC affects 600,000 individuals per year worldwide (25). Smoking has been implicated in the increased occurrence of HNSCC in developing countries. The role of HPV has emerged as an important factor in the increase in the incidence of oropharyngeal tumors affecting non-smokers in developed countries (26). In comparison with environment-related HNSCC, patients with HPV-related malignancies display a better response to treatment and a lower risk of death and tumor progression $(27,2,28-30)$. Therefore, we investigated the effects of 
A
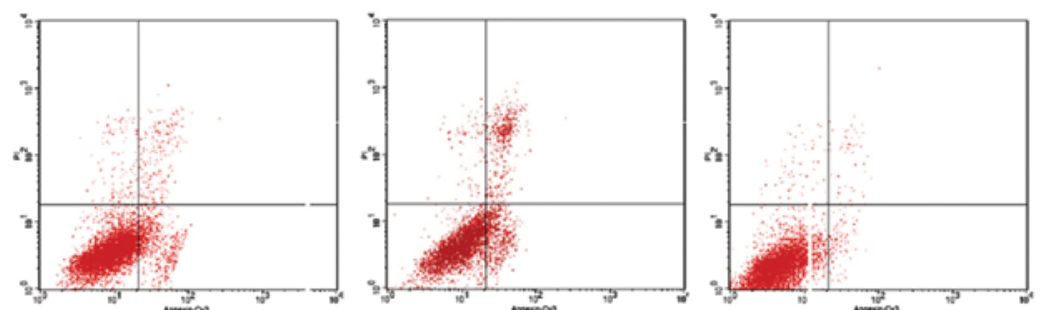

Blank control Empty vector control HPV-16 E6-E7

B

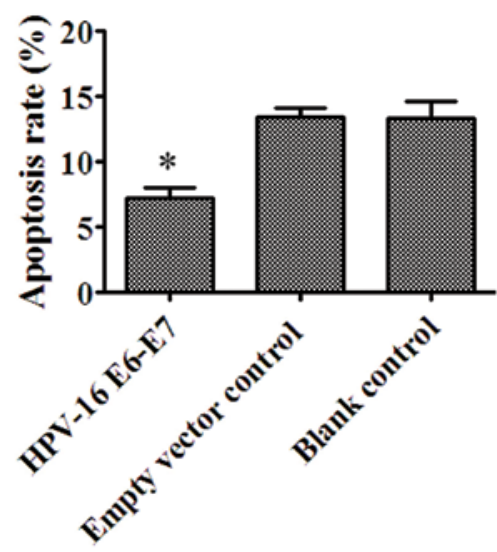

$\mathrm{C}$

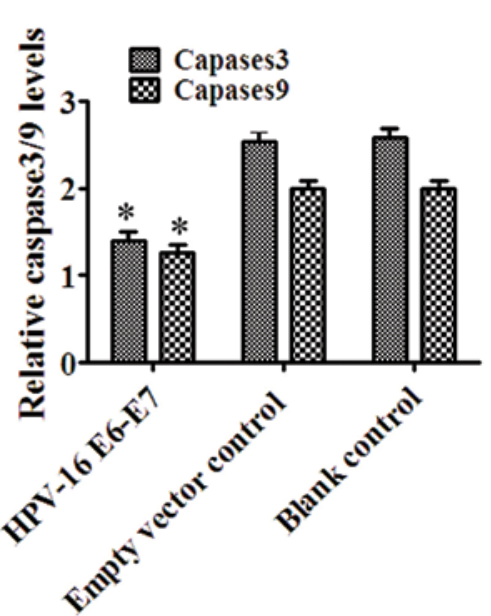

Figure 4. HPV-16 E6-E7 inhibits apoptosis. (A) The apoptosis of cells transfected with LV-HPV-16 E6-E7 was analyzed by apoptosis assay. (B) Significant $(\mathrm{P}<0.05)$ decreases in Annexin $\mathrm{V}^{+}$apoptotic cells were observed in the HPV-16 E6-E7-transfected FaDu cells. (C) Relative caspase-3/-9 levels. Data are presented as the mean of triplicate experiments ( $\mathrm{P}<0.05)$.

A

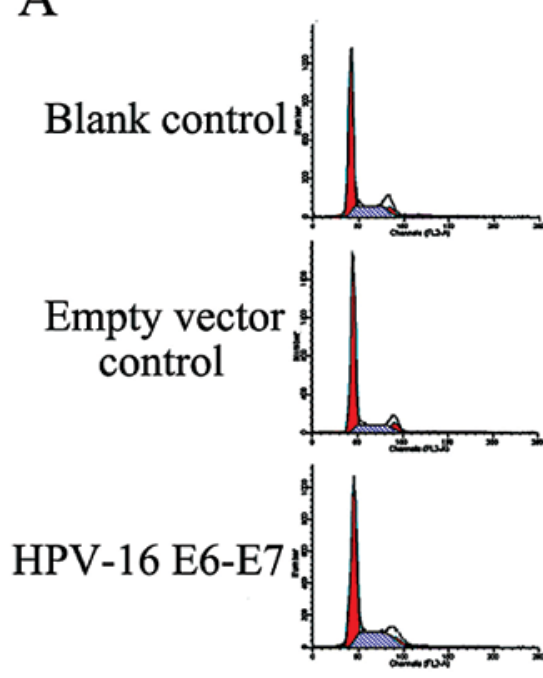

B

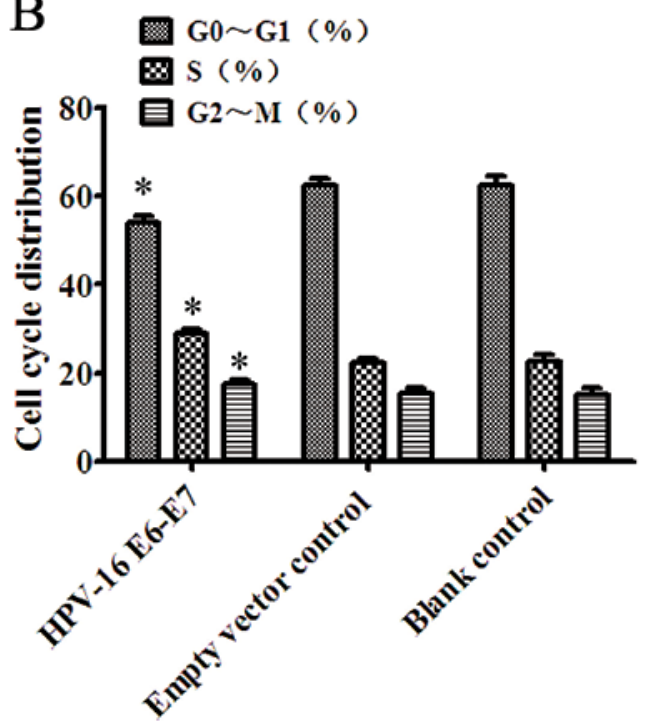

Figure 5. HPV-16 E6-E7 promotes cell cycle progression. (A) HPV-16 E6-E7 significantly decreased the percentage of cells in the G0/G1 phase, and significantly increased the S and G2/M phase fractions. (B) HPV-16 E6-E7 reduced cell cycle arrest in the G0/G1 phase, promoted the progression of the cell cycle and cell proliferation $\left({ }^{*} \mathrm{P}<0.05\right)$.

HPV-16 infection on the behavior of hypopharyngeal squamous cell carcinoma.

Of the 28 frozen hypopharyngeal squamous cell carcinoma tissues we examined, 7 were positive for the presence of HPV, with HPV-16 as the predominant genotype. We generated the LV-HPV-16-E6-E7 lentivirus to establish a FaDu cell line that stably expressed HPV-16 E6-E7. Our findings indicate that the E6-E7 proteins of HPV-16 inhibited apoptosis and increased the levels of proliferation, invasion and metastasis in the transfected FaDu cells.

In addition, we investigated miRNA expression levels in hypopharyngeal squamous cell carcinoma tissues and the 
A

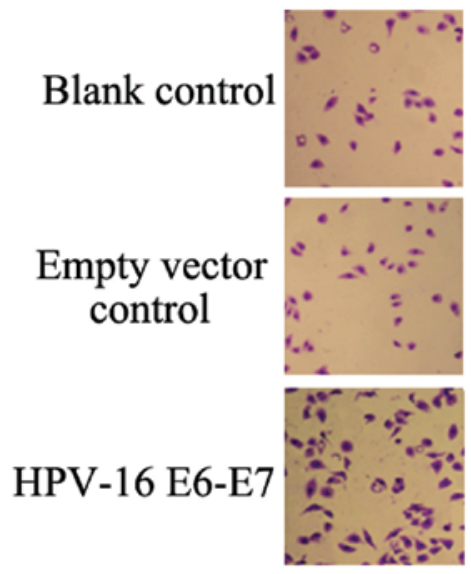

B

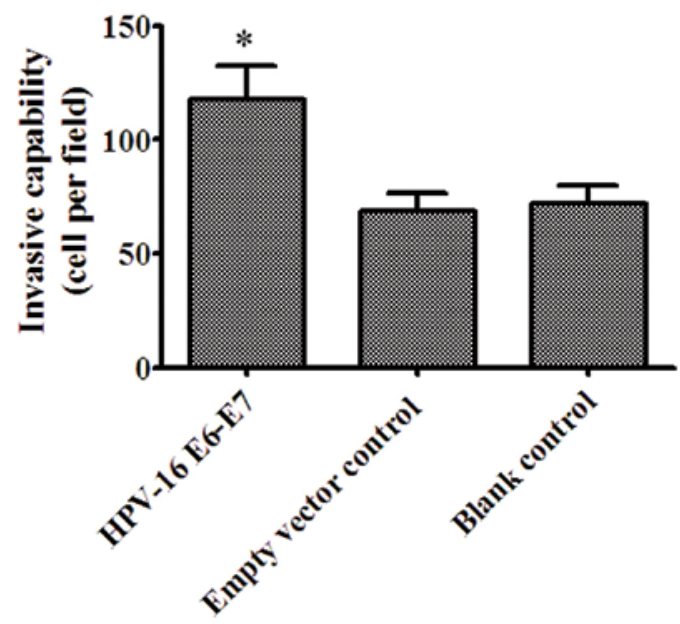

Figure 6. Invasive ability of FaDu cells was increased following transfection with HPV-16 E6-E7. (A) In vitro cell invasion assay showed that HPV-16 E6-E7 promoted the invasive ability of FaDu cells, compared to the control cells. (B) HPV-16 E6-E7 promoted the invasive ability of FaDu cells in vitro. ("P<0.05)

A

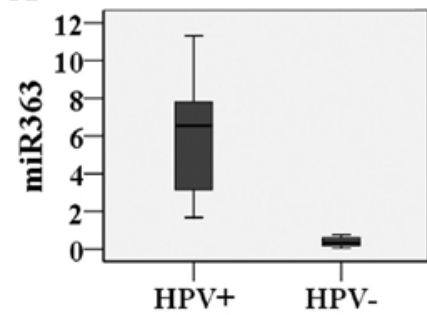

B

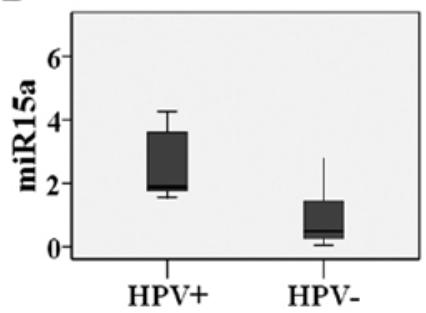

$\mathrm{C}$

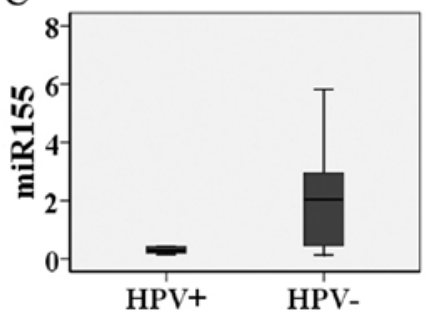

Figure 7. miR-363 and miR-15a are overexpressed in the HPV-positive pharyngeal squamous carcinoma tissues. The relative expression of miR-363 and miR15a were significantly higher in the HPV-positive tissues than the expression in the HPV-negative tissues while there was no significant change of miR-155 in both HPV positive/negative pharyngeal squamous carcinoma tissues and HPV-16 E6-E7-infected FaDu cells.

generated FaDu cell line. Results from previous studies have demonstrated that the miRNA expression profiles are altered in HNSCC and that these changes can be attributed to HPV infection $(31,32)$. We found that expression levels of miR-363, miR-33 and miR-497 were upregulated in the HPV-16-positive HNSCC cases. Expression levels of miR-181a, miR-181b, miR-29a and miR-218 were downregulated, and this was significant for miR-363 and miR-155.

Results from another study showed that miR-15a expression was upregulated in HPV-positive HNSCC. In the present study, we found that miR-15a was upregulated in the hypopharyngeal squamous cell carcinoma tissues and in LV-HPV-16-E6-E7-infected FaDu cells. This particular miRNA plays an important role as a tumor suppressor, and may be associated with a favorable prognosis in HPV-related HNSCC. It is possible that miR-15a could be used in the development of miRNA-based therapies for hypopharyngeal squamous cell carcinoma. We failed to observe any significant changes in miR-155 expression levels for HPV-positive/ negative hypopharyngeal squamous cell carcinoma tissues and LV-HPV-16-E6-E7-infected FaDu cells. Findings from previous studies have shown that miR-155 expression was significantly downregulated in HNSCC cells that were positive for HPV-16. We speculate that these contrasting results may be due to inconsistencies between tumor tissues and tumorderived cells, and since different detection methods were used. Future studies to assess the roles of miR-363, miR-15a, and miR-155 in hypopharyngeal squamous cell carcinoma are warranted.

\section{Acknowledgements}

We are grateful to Professor Guoqiang Zhao for helpful comments and suggestions during all stages of the project. This study was partially supported by the Scientific and Technological Foundation of Henan Province (no. 112102310679).

\section{References}

1. Akao Y, Nakagawa Y, Kitade Y, Kinoshita T and Naoe T: Downregulation of microRNAs-143 and -145 in B-cell malignancies. Cancer Sci 98: 1914-1920, 2007.

2. Ferlay J, Shin HR, Bray F, Forman D, Mathers C and Parkin DM: Estimates of worldwide burden of cancer in 2008: GLOBOCAN 2008. Int J Cancer 127: 2893-2917, 2010.

3. Ang KK, Harris J, Wheeler R, Weber R, Rosenthal DI, Nguyen-Tân PF, Westra WH, Chung CH, Jordan RC, Lu C, et al: Human papillomavirus and survival of patients with oropharyngeal cancer. N Engl J Med 363: 24-35, 2010. 
4. Stransky N, Egloff AM, Tward AD, Kostic AD, Cibulskis K, Sivachenko A, Kryukov GV, Lawrence MS, Sougnez C, McKenna A, et al: The mutational landscape of head and neck squamous cell carcinoma. Science 333: 1157-1160, 2011.

5. Cancer Genome Atlas Network: Comprehensive genomic characterization of head and neck squamous cell carcinomas. Nature 517: 576-582, 2015.

6. Cancer Genome Atlas Research Network: Comprehensive molecular characterization of clear cell renal cell carcinoma. Nature 499: 43-49, 2013.

7. Miller DL, Puricelli MD and Stack MS: Virology and molecular pathogenesis of HPV (human papillomavirus)-associated oropharyngeal squamous cell carcinoma. Biochem J 443: 339-353, 2012.

8. Funk JO, Waga S, Harry JB, Espling E, Stillman B and Galloway DA: Inhibition of CDK activity and PCNA-dependent DNA replication by $\mathrm{p} 21$ is blocked by interaction with the HPV-16 E7 oncoprotein. Genes Dev 11: 2090-2100, 1997.

9. Kehmeier E, Rühl H, Voland B, Stöppler MC, Androphy E and Stöppler H: Cellular steady-state levels of 'high risk' but not 'low risk' human papillomavirus (HPV) E6 proteins are increased by inhibition of proteasome-dependent degradation independent of their p53- and E6AP-binding capabilities. Virology 299: 72-87, 2002.

10. Gillison ML,D'Souza G, Westra W, SugarE, Xiao W, Begum S and Viscidi R: Distinct risk factor profiles for human papillomavirus type 16-positive and human papillomavirus type 16-negative head and neck cancers. J Natl Cancer Inst 100: 407-420, 2008.

11. Chaturvedi AK, Engels EA, Pfeiffer RM, Hernandez BY, Xiao W, Kim E, Jiang B, Goodman MT, Sibug-Saber M, Cozen W, et al: Human papillomavirus and rising oropharyngeal cancer incidence in the United States. J Clin Oncol 29: 4294-4301, 2011.

12. Karim R, Tummers B, Meyers C, Biryukov JL, Alam S, Backendorf C, Jha V, Offringa R, van Ommen GJ, Melief CJ, et al: Human papillomavirus (HPV) upregulates the cellular deubiquitinase UCHL1 to suppress the keratinocyte's innate immune response. PLoS Pathog 9: e1003384, 2013.

13. Hashibe M, Brennan P, Benhamou S, Castellsague X, Chen C, Curado MP, Dal Maso L, Daudt AW, Fabianova E, Fernandez L, et al: Alcohol drinking in never users of tobacco, cigarette smoking in never drinkers, and the risk of head and neck cancer: Pooled analysis in the International Head and Neck Cancer Epidemiology Consortium. J Natl Cancer Inst 99: 777-789, 2007.

14. Mork J, Lie AK, Glattre E, Hallmans G, Jellum E, Koskela P, Møller B, Pukkala E, Schiller JT, Youngman L, et al: Human papillomavirus infection as a risk factor for squamous-cell carcinoma of the head and neck. N Engl J Med 344: 1125-1131, 2001.

15. de Villiers EM, Fauquet C, Broker TR, Bernard HU and zur Hausen H: Classification of papillomaviruses. Virology 324: $17-27,2004$.

16. Muñoz N, Bosch FX, de Sanjosé S, Herrero R, Castellsagué X, Shah KV, Snijders PJ and Meijer CJ; International Agency for Research on Cancer Multicenter Cervical Cancer Study Group: Epidemiologic classification of human papillomavirus types associated with cervical cancer. N Engl J Med 348: 518-527, 2003.

17. Phelps WC, Barnes JA and Lobe DC: Molecular targets for human papillomaviruses: Prospects for antiviral therapy. Antivir Chem Chemother 9: 359-377, 1998.

18. Sandhu SK, Volinia S, Costinean S, Galasso M, Neinast R, Santhanam R, Parthun MR, Perrotti D, Marcucci G, Garzon R, et al: miR-155 targets histone deacetylase 4 (HDAC4) and impairs transcriptional activity of B-cell lymphoma 6 (BCL6) in the E $\mu$-miR-155 transgenic mouse model. Proc Natl Acad Sci USA 109: 20047-20052, 2012
19. Lenze D, Leoncini L, Hummel M, Volinia S, Liu CG, Amato T, De Falco G, Githanga J, Horn H, Nyagol J, et al: The different epidemiologic subtypes of Burkitt lymphoma share a homogenous micro RNA profile distinct from diffuse large B-cell lymphoma. Leukemia 25: 1869-1876, 2011.

20. Lajer CB, Nielsen FC, Friis-Hansen L, Norrild B, Borup R, Garnæs E, Rossing M, Specht L, Therkildsen MH, Nauntofte B, et al: Different miRNA signatures of oral and pharyngeal squamous cell carcinomas: A prospective translational study. $\mathrm{Br}$ J Cancer 104: 830-840, 2011.

21. Lace MJ, Anson JR, Klingelhutz AJ, Lee JH, Bossler AD, Haugen TH and Turek LP: Human papillomavirus (HPV) type 18 induces extended growth in primary human cervical, tonsillar, or foreskin keratinocytes more effectively than other high-risk mucosal HPVs. J Virol 83: 11784-11794, 2009.

22. Rahimy E, Kuo SZ and Ongkeko WM: Evaluation of non-coding RNAs as potential targets in head and neck squamous cell carcinoma cancer stem cells. Curr Drug Targets 15: 1247-1260, 2014.

23. Li M, Liu L, Zang W, Wang Y, Du Y, Chen X, Li P, Li J and Zhao G: miR-365 overexpression promotes cell proliferation and invasion by targeting ADAMTS-1 in breast cancer. Int J Oncol 47: 296-302, 2015

24. Schmittgen TD and Livak KJ: Analyzing real-time PCR data by the comparative C(T) method. Nat Protoc 3: 1101-1108, 2008

25. Walter V, Yin X, Wilkerson MD, Cabanski CR, Zhao N, Du Y, Ang MK, Hayward MC, Salazar AH, Hoadley KA, et al: Molecular subtypes in head and neck cancer exhibit distinct patterns of chromosomal gain and loss of canonical cancer genes. PLoS One 8: e56823, 2013.

26. Lajer CB and von Buchwald C: The role of human papillomavirus in head and neck cancer. APMIS 118: 510-519, 2010.

27. Scheffner M, Huibregtse JM, Vierstra RD and Howley PM: The HPV-16 E6 and E6-AP complex functions as a ubiquitin-protein ligase in the ubiquitination of p53. Cell 75: 495-505, 1993.

28. Fakhry C, Westra WH, Li S, Cmelak A, Ridge JA, Pinto H, Forastiere A and Gillison ML: Improved survival of patients with human papillomavirus-positive head and neck squamous cell carcinoma in a prospective clinical trial. J Natl Cancer Inst 100: 261-269, 2008

29. Flores ER, Allen-Hoffmann BL, Lee D and Lambert PF: The human papillomavirus type $16 \mathrm{E} 7$ oncogene is required for the productive stage of the viral life cycle. J Virol 74: 6622-6631, 2000.

30. O'Rorke MA, Ellison MV, Murray LJ, Moran M, James J and Anderson LA: Human papillomavirus related head and neck cancer survival: A systematic review and meta-analysis. Oral Oncol 48: 1191-1201, 2012.

31. Wald AI, Hoskins EE, Wells SI, Ferris RL and Khan SA: Alteration of microRNA profiles in squamous cell carcinoma of the head and neck cell lines by human papillomavirus. Head Neck 33: 504-512, 2011.

32. Lajer CB, Garnæs E, Friis-Hansen L, Norrild B, Therkildsen MH, Glud M, Rossing M, Lajer H, Svane D, Skotte L, et al: The role of miRNAs in human papilloma virus (HPV)-associated cancers: Bridging between HPV-related head and neck cancer and cervical cancer. Br J Cancer 106: 1526-1534, 2012. 